\title{
A Comparative Study of the Antioxidant Properties of Three Pineapple (Ananas comosus L.) Varieties
}

\author{
Anynda Yuris \\ School of Science, Monash University Malaysia \\ Jalan Lagoon Selatan, 46150 Bandar Sunway, Selangor, Malaysia \\ Tel: 64-22-191-0574Ｅ-mail: yurisanynda@gmail.com \\ Lee-Fong Siow (Corresponding author) \\ School of Science, Monash University Malaysia \\ Jalan Lagoon Selatan, 46150 Bandar Sunway, Selangor, Malaysia \\ Tel: 60-3-5514-6034Ｅ-mail: siow.lee.fong@monash.edu
}

Received: January 27, 2014 Accepted: March 4, 2014 Published: December 1, 2014

doi:10.5296/jfs.v3i1.4995 URL: http://dx.doi.org/10.5296/jfs.v3i1.4995

\begin{abstract}
The objective of this study was to determine the antioxidant activity of different pineapple varieties namely Josephine (Ananas comosus L. var. comosus cv. Josephine), Morris (Ananas comosus L. var. comosus cv. Morris), and Sarawak (Ananas comosus L. var. comosus cv. Sarawak). Different concentrations of methanol, ethanol, and acetone were used to extract the phenolic compounds. Folin Ciocalteu's reagent was used to determine the total phenolic content. The ascorbic acid content of the fruit extracts was determined using the iodine titration method. The antioxidant activity of the pineapples was measured using the 2,2-diphenyl-1-picryhydrzyl (DPPH) radical scavenging assay, the Ferric Reducing Power (FRP) assay and the Ferrous Ion Chelating (FIC) assay. 50\% methanol was chosen as the best solvent for extracting the phenolic compounds of the pineapples. Morris pineapple was found to contain the highest TPC $(53.8 \pm 0.7 \mathrm{mg}$ GAE$/ 100 \mathrm{~g}$ fruits $)$ and antioxidant activity. This variety was also found to have the highest DPPH scavenging activity $(25.2 \pm 0.5 \mathrm{mg} \mathrm{AA} / 100 \mathrm{~g}$ fruits), FRP (29.6 mg GAE/100g fruits) and FIC ability (8\%/100g fruits). Despite having a higher TPC than the Sarawak variety, Josephine exhibited a low scavenging activity. Strong positive correlations $\left(\mathrm{R}^{2}=0.9943\right)$ were observed between the ascorbic acid content and
\end{abstract}




\section{Macrothink}

Journal of Food Studies ISSN 2166-1073 2014, Vol. 3, No. 1

scavenging activity, as well as between TPC and FRP $\left(\mathrm{R}^{2}=0.9475\right)$. Only a weak correlation $\left(\mathrm{R}^{2}=0.158\right)$ was observed between corrected TPC and FRP. FIC ability was observed in all the extracts.

Keywords: Pineapple, Antioxidant, DPPH radical scavenging, Ferric Reducing Power, Ferrous Ion Chelating 


\section{MInstitute"}

\section{Introduction}

\subsection{Pineapple}

Pineapple (Ananas comosus L.) is a fruit which belongs to the Bromeliaceae family. This fruit is cultivated in most tropical and subtropical countries (Carlier, Sousa, Santo, d'Eeckenbrugge \& Leitao, 2010). Ranking third among tropical fruits in world production, Ananas comosus is the only member of the family Bromeliaceae that bears edible fruits (Kudom \& Kwapong, 2010). The pineapple plant is a tropical, herbaceous, perennial monocot. It can grow up to approximately $1-2$ meters tall with spirally arranged leaves. The flowers of this plant bloom on a terminal inflorescence, growing into a large edible fruit with a tuft of leaves on its apex (Kudom \& Kwapong, 2010).

Several varieties of pineapples can be found in Malaysia. Three of the common varieties are Josephine (Ananas comosus L. var. comosus cv. Josephine), Morris (Ananas comosus L. var. comosus cv. Morris) and Sarawak (Ananas comosus L. var. comosus cv. Sarawak) (Figure 1). Josephine is a pineapple variety which has high sugar content $\left(16-17^{\circ} \mathrm{Brix}\right)$. It is smaller in size compared to the Morris and Sarawak varieties. The Morris pineapple (sometimes referred to as Queen Pineapple) also has a high sugar content of around $13-18{ }^{\circ}$ Brix. The flesh of this variety is golden-yellow in color with spineless leaves. The Morris variety is smaller in size compared to the Sarawak variety (which is also known as the Smooth Cayenne) (De Silva, Kadir, Aziz \& Kadzimin, 2008). This pineapple variety has a good sugar-acid balance as well as flavour (Bartolome, Ruperez \& Fuster, 1994). These pineapple varieties were used in the current study as there was no information available on these pineapple varieties and they are commonly available in tropical country.

Pineapple has widely been consumed as jam, jelly, juice, as a dried product, or as fresh fruit. Pineapple is a rich source of vitamin $\mathrm{A}, \mathrm{B}$, and $\mathrm{C}$ as well as the minerals calcium, phosphorous, and iron. Pineapple juice has traditionally been used to alleviate sore throats and seasickness. The bioactivity of this fruit is due to the presence of compounds such as polyphenols and ascorbic acid, which contribute to the antioxidant activity of the fruit extract (Hossain \& Rahman, 2010). Study has shown that pineapples contain flavonoids (Hossain \& Rahman, 2010), phenolic compounds, namely the quercetin, flavones-3-ol, flavones (Mhatre, Tilak-Jain, De \& Devasagayam, 2009), p-coumaric acid and ferulic acid (Hui, 2007), and vitamin C (Kongsuwan, Suthiluk, Theppakorn, Srilaong \& Setha, 2009). 


\section{Macrothink}

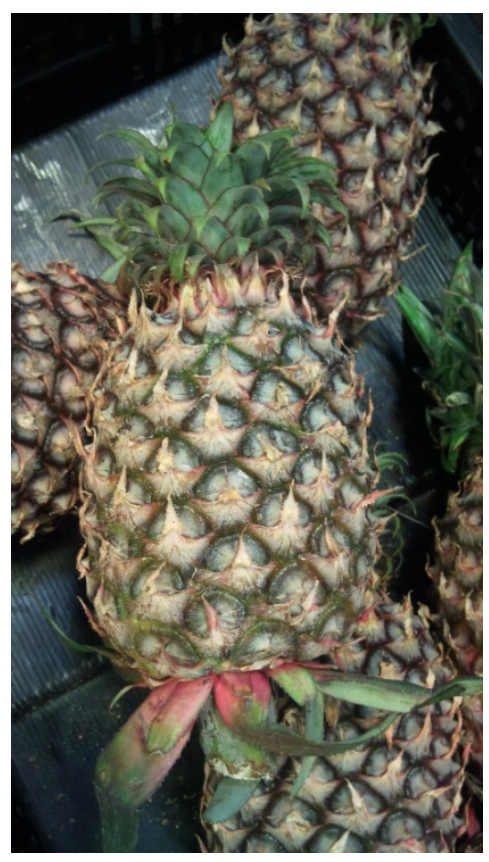

(a.)

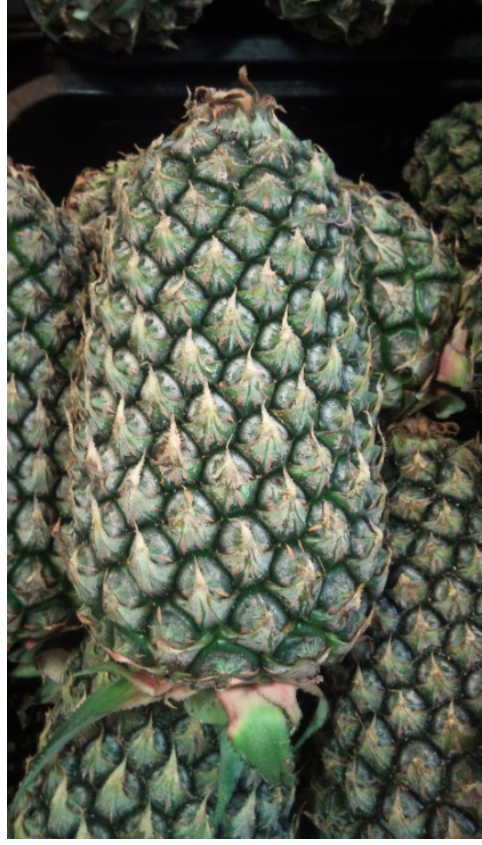

(b.)

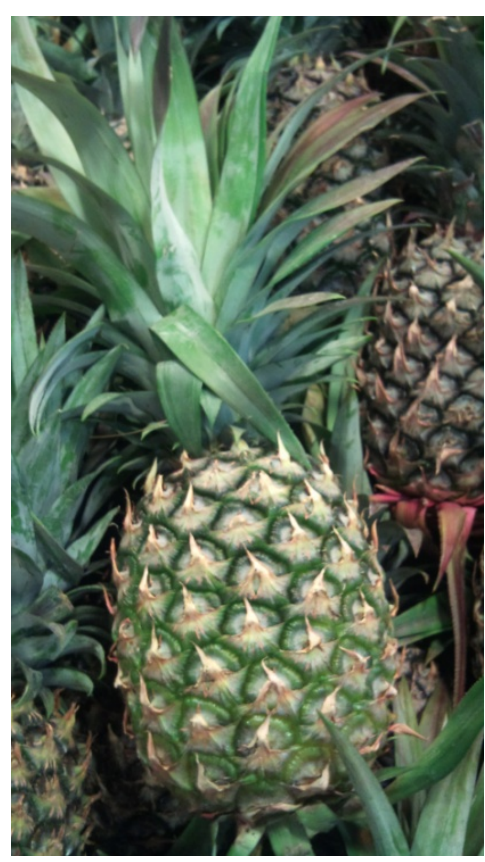

(c.)

Figure 1. Three pineapple varieties: (a) Josephine, (b) Morris and (c) Sarawak

\subsection{Antioxidants}

Antioxidant is defined as compounds that protect against oxidation by increasing the oxidative stability of a system (Damodaran, Parkin \& Fennema., 2008). Antioxidants can be obtained either synthetically or naturally. Due to the possible hazardous effect of synthetic antioxidants, there is an increasing interest in natural antioxidants such as those in fruits and vegetables (Frankel, 2007; Hossain \& Rahman, 2010). Epidemiological studies have shown that an increase in fruit intake is associated with a reduced morbidity of cardiovascular disease, some types of cancer, and neurodegenerative diseases (Guo et al., 2003; Reddy, Sreermulu \& Raghunath, 2010; Moure et al., 2001; Lima, Pimenta \& Boaventura, 2010; Kou et al., 2009). A possible mechanism for this observation has been attributed to the antioxidant activity in fruits (Guo et al., 2003, Moure et al., 2001, Kou et al., 2009). Both the phenolic content and ascorbic acid content of fruits are responsible for their antioxidant activity.

The antioxidant activity of phenolics can generally be divided into two groups: primary and secondary antioxidants. Primary antioxidants terminate chain reactions. This could occur by mechanisms such as the donation of electron or hydrogen to the free radical, forming a stable compound. Secondary antioxidants, on the other hand, prevent the initiation of free radical chain reactions by mechanisms such as metal chelation (Moure et al., 2001; Haripyaree, Guneshwor \& Damanyati, 2010).

A study by Alothman, Bhat \& Karim (2009) showed that varying concentrations of different solvents were able to extract different amount of phenolic contents in an unknown variety of pineapple. In another study by Hossain \& Rahman (2010), it was reported that methanol was able to extract higher amount of phenolic compounds compared to water and ethyl acetate in 
Calendar pineapples. The ability of pineapple extracts to scavenge DPPH, superoxide, and hydroxyl radicals have been reported in several studies (Haripyaree et al., 2010; Kongsuwan et al., 2009). Although pineapples have been shown to possess antioxidant activities, no information was available on the antioxidant properties of the three pineapple varieties selected in this study. Hence, the objective of this study was to determine the suitable solvent system to extract the phenolic contents of the three pineapple varieties and to determine the antioxidant activity using three antioxidant assays.

\section{Materials and Methods}

\subsection{Plant Material}

Fresh Josephine, Morris, and Sarawak pineapples were obtained from the local hypermarket between the months of March and May. Each pineapple variety was selected visually by choosing those that are of the same size, firmness, and skin colour. The pineapples were ensured to have no external defect (indicated by the secretion of liquid). They were also ensured not to be overripe based on the aroma as an extremely sweet aroma indicates over ripeness. A refractometer (Atago Master-T, Japan) was then used to determine the ${ }^{\circ}$ Brix of the pineapples and those within the range of $23 \pm 5^{\circ}$ Brix were selected.

\subsection{Sample extraction}

Sample extraction was performed according to the method described by Lim et al. (2007). Five Josephine pineapples were skinned and homogenized using a blender (Kenwood, FP220, U.K.) into paste. Depending on the test to be performed, either $10 \mathrm{~g}$ or $40 \mathrm{~g}$ of the paste was weighed in a beaker and $100 \mathrm{~mL}$ of water was added. The mixture was placed in an orbital shaker (LABWIT incubator shaker, ZHWY-200b, Shanghai) for the extraction at a speed of $150 \mathrm{rpm}$ for 10 minutes at room temperature. The mixture was then filtered through a muslin cloth and the extract was centrifuged (Hettich Zentrifugen Universal, 320R, Germany) at room temperature with a speed of $4750 \mathrm{~g}$ for 15 minutes. The extract was then stored at $-20{ }^{\circ} \mathrm{C}$ for no more than 1 week. The same extraction procedure was repeated for Morris and Sarawak varieties. All extractions were repeated using $50 \%$ or $70 \%$ of methanol, ethanol or acetone respectively.

\subsection{Determination of ascorbic acid content}

\subsubsection{Standardization of iodine}

Iodine solution $(0.05 \mathrm{M})$ was prepared and standardized according to Suntornsuk et al. (2002) with slight modification. Two g of potassium iodide was dissolved in $10 \mathrm{~mL}$ of distilled water. $1.3 \mathrm{~g}$ of iodine was then added to $10 \mathrm{~mL}$ of the potassium iodide solution. The solution was acidified using $2 \mathrm{~mL}$ of $1 \mathrm{M}$ hydrochloric acid and diluted to a final volume of $100 \mathrm{~mL}$ using distilled water. Arsenic trioxide solution was prepared by adding $0.0118 \mathrm{~g}$ of Arsenic trioxide into $10 \mathrm{~mL}$ of $1 \mathrm{M} \mathrm{NaOH}$ followed by $10 \mathrm{~mL}$ of distilled water. The solution was acidified by adding $1 \mathrm{M} \mathrm{HCl}$ followed by the addition of $\mathrm{NaHCO}_{3}(0.5 \mathrm{~g})$, distilled water $(12.5 \mathrm{~mL})$ and 2 $\mathrm{mL}$ of $1 \%$ starch solution. The iodine solution was diluted to a final concentration of $0.005 \mathrm{M}$. Standardization was carried out by titrating the arsenic trioxide solution against the iodine 
solution.

\subsubsection{Iodine titration method}

Ascorbic acid present in the extract was determined using the iodine titration method (Suntornsuk, Kritsanapun, Nilkamhank \& Paochom, 2002). Forty grams of pineapple varieties were extracted. Each extract $(5 \mathrm{~mL})$ was added with $5 \mathrm{~mL}$ of $4 \%$ metaphosphoric acid, $5 \mathrm{~mL}$ of $1 \mathrm{M}$ sulphuric acid, and $2 \mathrm{~mL}$ of $1 \%$ starch solution. The mixture was then titrated against $0.001 \mathrm{M}$ iodine solution which was diluted from the standardized iodine solution.

\subsection{Determination of antioxidant properties}

\subsubsection{Determination of total phenolic content (TPC)}

TPC was determined using the Folin-Ciocalteu's reagent (Singleton \& Rossi, 1965). Sample extract $(0.3 \mathrm{~mL})$ was added with $1.5 \mathrm{~mL}$ Folin Ciocalteu's reagent that had been diluted 10 times. $1.2 \mathrm{~mL}$ of $7.5 \% \mathrm{w} / \mathrm{v}$ sodium carbonate was then added. The mixture was allowed to stand for 30 minutes before reading the absorbance at $765 \mathrm{~nm}$. Solvent was used to replace the extract as the blank. A standard curve was prepared using gallic acid diluted to different concentrations. Water was used as a blank to replace the gallic acid. The ascorbic acid content of pineapples was determined to correct the TPC reading. This was done by determining the absorbance contributed by ascorbic acid and subtracting this reading from the initial absorbance reading

\subsubsection{2,2-diphenyl-1-picryhydrzyl (DPPH) free radical scavenging assay}

The DPPH free radical scavenging activity of the extract was determined using the method described by Krings \& Berger (2001) with slight modifications. Ten grams of each of the pineapple varieties were extracted. The sample extracts were diluted to a total of $2 \mathrm{~mL}$. Two $\mathrm{mL}$ of $0.15 \mathrm{mM}$ DPPH solution in methanol was added to each of the extracts. The mixture was left to stand for 30 minutes before reading the absorbance at $517 \mathrm{~nm}$. Methanol was used as the blank. Control was prepared using $2 \mathrm{~mL}$ of the solvent in place of the extract. Standard curve was prepared using ascorbic acid solution of different concentrations, with water as the blank. Water was used as a control to replace ascorbic acid. The \% inhibition of the extract was determined as equation (1), where $\mathrm{A}$ is absorbance:

$$
\% \text { inhibition }=\left[\left(\mathrm{A}_{\text {control }}-\mathrm{A}_{\text {sample }}\right) / \mathrm{A}_{\text {control }}\right] \times 100 \%
$$

The $\mathrm{IC}_{50}$ of ascorbic acid and the extract were then obtained by plotting the graph of $\%$ inhibition against the total phenol content of the extract. The final result was then expressed as ascorbic acid equivalence antioxidant capacity (AEAC). The AEAC was obtained using the following equation (2):

$$
\operatorname{AEAC}(\mathrm{mg} \mathrm{AA} / 100 \mathrm{~g})=\left[\mathrm{IC}_{50(\text { ascorbic acid })} / \mathrm{IC}_{50 \text { (sample) }}\right] \times 10^{5}
$$

\subsubsection{Ferric reducing power assay}

The ferric reducing power of the extract was determined using the method described by 
Oyaizu (1986). Ten grams of each of the pineapple varieties were extracted. One milliliter of the extract was added with $2.5 \mathrm{~mL}$ of $0.2 \mathrm{M}$ Phosphate buffer $(\mathrm{pH} 6.6$ ). 1\% potassium ferricyanide $(2.5 \mathrm{~mL})$ was added and the mixture was incubated for 20 minutes at $50^{\circ} \mathrm{C}$. The mixture was then added with $2.5 \mathrm{~mL}$ of $10 \%$ trichloroacetic acid. This mixture $(2.5 \mathrm{~mL})$ was added with $2.5 \mathrm{~mL}$ distilled water and $0.5 \mathrm{~mL}$ of $1 \%$ iron (III) chloride. The mixture was left to stand for 30 minutes. The absorbance was measured at $700 \mathrm{~nm}$ using water as the blank. Standard curve was prepared using gallic acid of different concentration in place of the extract.

\subsubsection{Ferrous ion chelating assay}

The ferrous ion chelating ability of the extract was determined using the method described by Carter (1971) with slight modifications. Forty grams of each of the pineapple varieties were extracted. Sample $(1 \mathrm{~mL})$ was prepared and added with $1 \mathrm{~mL}$ of $0.1 \mathrm{mM}$ iron (II) sulphate followed by $1 \mathrm{~mL}$ of $0.25 \mathrm{mM}$ ferrozine. The mixture was left for 10 minutes before reading the absorbance at $562 \mathrm{~nm}$. Blanks were prepared by replacing ferrozine with $1 \mathrm{~mL}$ distilled water for each dilution of the extract. Control was prepared by replacing the sample extract with $1 \mathrm{~mL}$ of the solvent. The chelating abilities of the extracts were then determined as equation (3):

$$
\% \text { Chelating }=\left(\mathrm{A}_{\text {control }}-\mathrm{A}_{\text {sample }}\right) / \mathrm{A}_{\text {control }} \times 100 \%
$$

\subsection{Data analysis}

All data was reported as means \pm standard deviation, where $n=3$. One-way ANOVA with Tukey test as the post hoc test was performed as the parametric test using SPSS 16. The Kruskal-Wallis test was performed as the non-parametric test using MedCalc. $\mathrm{P} \leq 0.05$ indicates significant differences between samples.

\section{Results and discussions}

\subsection{Extraction efficiency}

Alothman et al. (2009) reported that the amount of phenolic compounds extracted from pineapples is influenced by the type and concentration of the solvent used. The authors reported that the best extraction of an unknown pineapple variety was obtained when $90 \%$ or $50 \%$ acetone was used. In the same study, it was also found that good extraction can be obtained when methanol or ethanol were used at $50 \%$ and $70 \%$. In another study which also investigated the ability of different solvents to extract the phenolic compounds in pineapple, it was found that methanol at an unknown concentration extracted the highest phenolic content of the Calendar pineapple compared to water and ethyl acetate (Hossain \& Rahman, 2010). Based on the study by Alothman et al. (2009) who demonstrated high extraction efficiency at $50 \%$ and $70 \%$ of solvents, this study has adopted these concentrations to extract the phenolic contents of the pineapples. Water was also used in the extraction in order to investigate its efficiency and predict the polarity of the phenolic compounds in the pineapple. A higher TPC was observed in the 50\% methanolic extracts compared to other extracts of the three pineapple varieties (Table 1). However, these TPC values were not significantly $(p>0.05)$ 


\section{Macrothink

different for $50 \%$ acetone in the Morris variety and $50 \%$ or $70 \%$ acetone in the Sarawak variety. In the current study, 50\% methanol was chosen as the solvent to extract the three pineapples in subsequent studies because of its ability to inhibit polyphenol oxidase, which may react with phenolic compounds, thus altering their antioxidant activity (Robards, 2003). The extraction of phenolic compounds in plant materials is dependent on the solubility and polarity of the phenolic compounds in the solvent used for the extraction process (Alothman et al., 2009). In the current study, it is suggested that the phenolic compounds present in the three pineapple varieties are mostly polar since TPC ranging from $30.0 \mathrm{mg}$ GAE/100 $\mathrm{g}$ fruit to $53.8 \mathrm{mg} \mathrm{GAE} / 100 \mathrm{~g}$ was observed in methanolic extracts (Table 1). This was higher than most of the other extracts observed in this study.

Table 1. Total phenolic content of Josephine, Morris and Sarawak pineapple varieties extracted using different solvents

\begin{tabular}{|l|l|l|l|}
\hline \multirow{2}{*}{ Solvent } & \multicolumn{3}{|c|}{ TPC (mg GAE/100 g fruit) } \\
\cline { 2 - 4 } & Josephine & Morris & Sarawak \\
\hline $50 \%$ Methanol & $49.1 \pm 0.4^{\mathrm{d}}$ & $53.8 \pm 0.7^{\mathrm{df}}$ & $36.0 \pm 2.0^{\mathrm{e}}$ \\
\hline $70 \%$ Methanol & $47.5 \pm 0.6^{\mathrm{cd}}$ & $49.2 \pm 0.4^{\mathrm{ef}}$ & $30.0 \pm 0.3^{\mathrm{c}}$ \\
\hline $50 \%$ Ethanol & $43.0 \pm 0.3^{\mathrm{a}}$ & $44.7 \pm 2.0^{\mathrm{ab}}$ & $27.6 \pm 0.5^{\mathrm{b}}$ \\
\hline $70 \%$ Ethanol & $42.7 \pm 0.3^{\mathrm{a}}$ & $46.5 \pm 1.5^{\mathrm{abc}}$ & $30.1 \pm 0.8^{\mathrm{c}}$ \\
\hline $50 \%$ Acetone & $45.8 \pm 1.0^{\mathrm{bc}}$ & $49.3 \pm 0.7^{\mathrm{def}}$ & $32.9 \pm 0.1^{\mathrm{d}}$ \\
\hline $70 \%$ Acetone & $45.0 \pm 0.5^{\mathrm{abc}}$ & $47.1 \pm 1.1^{\mathrm{ac}}$ & $33.5 \pm 0.8^{\mathrm{de}}$ \\
\hline Water & $44.4 \pm 2.2^{\mathrm{ab}}$ & $46.4 \pm 0.2^{\mathrm{abc}}$ & $22.7 \pm 0.7^{\mathrm{a}}$ \\
\hline
\end{tabular}

Values are the mean \pm SD of $n=3$

Within a column, different letters show significant differences $(\mathrm{P} \leq 0.05)$ between different solvents

\subsection{Ascorbic acid content and correction of TPC}

The ascorbic acid contents were significantly different $(\mathrm{p} \leq 0.05)$ among the pineapple varieties (Table 2). The ascorbic acid content of Josephine and Sarawak varieties were comparable to that of the "Nanglae" (6.45 mg AA/100 g fruit) and "Phulae" (18.88 mg AA/100 g fruit) pineapples as reported by Kongsuwan et al. (2009). The ascorbic acid content of the Sarawak variety was similar to that have been previously reported by Valente, Albuquerque, Sanches-Silva and Costa (2011) whereby they determined the ascorbic acid content of the Cayenne cultivar to be $11.0 \mathrm{mg} \mathrm{AA} / 100 \mathrm{~g}$ fruits. In the current study, ascorbic acid content of the Morris variety was either higher or lower than reported literature values (Isabelle et al., 2010; Kongsuwan et al., 2009; Valente et al., 2011). The varieties of pineapple that were used in these previous studies were unknown. 
Table 2. The ascorbic acid content for Josephine, Morris and Sarawak pineapple varieties

\begin{tabular}{|l|l|}
\hline Pineapple & Ascorbic acid content $\mathbf{( m g / 1 0 0 ~ g ~ f r u i t )}$ \\
\hline Josephine & $7.70 \pm 0.67^{\mathrm{a}}$ \\
\hline Morris & $27.8 \pm 1.16^{\mathrm{b}}$ \\
\hline Sarawak & $15.0 \pm 0.00^{\mathrm{c}}$ \\
\hline
\end{tabular}

Values are the mean $\pm \mathrm{SD}$ of $\mathrm{n}=3$

Within a column, different lower case letters show significant differences $(\mathrm{P} \leq 0.05)$ between different pineapples

Since ascorbic acid contributes to the TPC reading, it has the ability to reduce the Folin reagent, thus resulting in the Prussian blue chromophore (Isabelle et al., 2010; Makkar, 2003). The TPC readings were corrected with the ascorbic acid readings (Table 3). There were significant differences $(\mathrm{p} \leq 0.05)$ among the TPC content and corrected TPC content for the three pineapple varieties (Table 3). The variation in TPC content had been suggested to be a contribution of several factors such as the varieties themselves (Contreras-Calderon, Calderon-James, Guerra-Hernandez \& Gacia-Villanova, 2010), ripeness (Contreras-Calderon et al., 2010) and growing conditions that include climate, location and soil composition (Isabelle et al., 2010). There was also a significant difference $(\mathrm{p} \leq 0.05)$ between the value of the TPC and corrected TPC for each of the pineapples. This indicates that ascorbic acid contributes to the initial TPC reading. The TPC reading is also contributed by other reducing agents such as amino acids (Makkar, 2003). The TPC reading, therefore, estimates the reducing capacity of the sample but TPC value per se could not be used to compare the phenolic contents among samples (Vermerris \& Nicholson, 2008).

Table 3. The TPC and corrected TPC for the methanolic extracts of Josephine, Morris and Sarawak pineapple varieties

\begin{tabular}{|l|l|l|}
\hline Pineapple & TPC (mg GAE/100 g fruit) & Corrected TPC (mg GAE/100 g fruit) \\
\hline Josephine & $49.1 \pm 0.4^{\mathrm{aA}}$ & $41.9 \pm 0.6^{\mathrm{aB}}$ \\
\hline Morris & $53.8 \pm 0.7^{\mathrm{bA}}$ & $27.8 \pm 0.7^{\mathrm{bB}}$ \\
\hline Sarawak & $36.0 \pm 2.0^{\mathrm{cA}}$ & $22.0 \pm 2.0^{\mathrm{cB}}$ \\
\hline
\end{tabular}

Values are the mean $\pm \mathrm{SD}$ of $\mathrm{n}=3$

Within a column, different lower case letters show significant differences $(\mathrm{P} \leq 0.05)$ between different pineapples

Within a row, different upper case letters show significant differences $(\mathrm{P} \leq 0.05)$ between different pineapples

\subsection{Antioxidant activity of extract}

\subsubsection{DPPH}

The $\mathrm{IC}_{50}$ of the extract defines the amount of the extract needed to scavenge $50 \%$ of the $\mathrm{DPPH}$ radical. It was seen that the AEAC content among the three pineapples were 


\section{Macrothink

significantly different $(\mathrm{p} \leq 0.05)$ with Morris being the highest, followed by Sarawak and Josephine. It was also noted that Josephine with a high TPC exhibited the lowest AEAC (Table 4). A similar trend was observed in a study conducted by Kongsuwan et al. (2009). He reported that the "Phulae" (18.88 $\mathrm{mg} \mathrm{AA} / 100 \mathrm{~g}$ fruit) pineapples which have a higher TPC content compared to the "Nanglae" (6.45 mg AA/100 g fruit) pineapples exhibited a lower DPPH scavenging ability. A similar observation was also made by Lim et al. (2007), whereby the authors reported a low AEAC but relatively high TPC value in langsat. There is a possibility that the phenolic compound present in the fruit extract has a slow rate of reaction with the DPPH radicals, resulting in a low AEAC reading (Lim et al., 2007). The current study suggests that the phenolic compounds present in the pineapple extracts are not the main contributor to the radical scavenging activity of the extracts.

Table 4. The AEAC and $\mathrm{IC}_{50}$ for the extracts of Josephine, Morris and Sarawak pineapple varieties

\begin{tabular}{|l|l|l|}
\hline Pineapple & AEAC $(\mathbf{m g}$ AA/100 g) & IC $_{\mathbf{5 0}} \mathbf{( m g / m L )}$ \\
\hline Josephine & $10.8 \pm 0.1^{\mathrm{a}}$ & $29.0 \pm 0.2^{\mathrm{a}}$ \\
\hline Morris & $25.2 \pm 0.5^{\mathrm{b}}$ & $12.4 \pm 0.3^{\mathrm{b}}$ \\
\hline Sarawak & $17.1 \pm 0.5^{\mathrm{c}}$ & $18.4 \pm 0.6^{\mathrm{c}}$ \\
\hline
\end{tabular}

* $\mathrm{IC}_{50}$ ascorbic acid: $3.14 \times 10^{-3} \mathrm{mg} / \mathrm{mL}$

Values are the mean $\pm \mathrm{SD}$ of $\mathrm{n}=3$

Within a column, different lower case letters show significant differences $(\mathrm{P} \leq 0.05)$ between different pineapples

When the ascorbic acid content of each pineapple was plotted against their respective AEAC, a strong correlation between the two was observed $\left(\mathrm{R}^{2}=0.9943\right)$ (Figure 2). Ascorbic acid is a free radical scavenger which has a very fast reaction compared to other radical scavenging molecules such as the phenolic compounds (Scalzo, 2008). Hence, ascorbic acid could probably be the main contributor towards the radical scavenging activity of the pineapple extracts. 


\section{$\underline{\Lambda \text { Macrothink }}$}

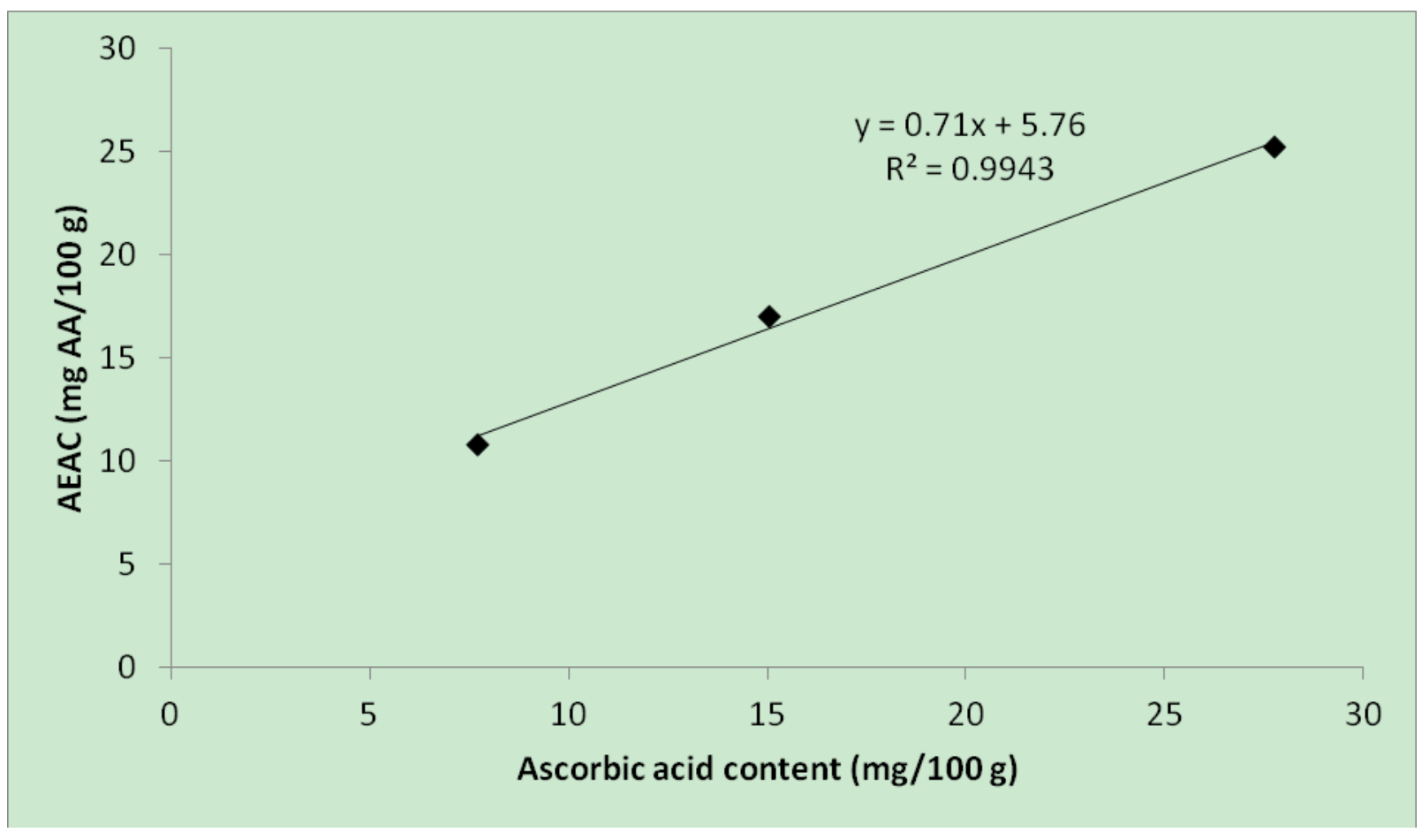

Figure 2. The correlation between the Ascorbic acid content and the radical scavenging ability (AEAC) in Josephine, Morris and Sarawak pineapple

\subsubsection{Ferric reducing power}

Ferric reducing power assay shows the ability of the extract to donate electron to ferric ion, reducing it into ferrous ion. It was observed that the FRP among the three extracts were significantly different $(\mathrm{p} \leq 0.05)$ from each other; with Morris is the highest followed by Josephine and Sarawak (Figure 3). The FRP of the extracts ranging between approximately $18.2-29.6 \mathrm{mg} \mathrm{GAE} / 100 \mathrm{~g}$ of fruit. This value is extremely low compared to young Camellia sinensis leave extract, which has been reported with an FRP value of approximately $5450 \mathrm{mg}$ GAE/100 g of leaves (Chan, Lim \& Chew, 2007). Tea leaves had been reported to contain catechins such as the epigallocatechin galate (EGCG), epigallocatechin (EGC), epicatechin gallate (ECG), gallocatechin (GC), epicatechin (EC) and tannic acid (de Mejia, Ramirez-Mares \& Puangpraphant, 2009). Cathechin and tannic acid have both been shown to contribute to FRP in which tannic acid's contribution is especially high (Maqsood \& Benjakul, 2010). Apart from these two compounds, the same study by Maqsood \& Benjakul (2010), also showed that caffeic acid and ferulic acid had a contribution towards the FRP value. Pineapples have been reported to contain ferulic acid (Hui, 2007). This suggests that the FRP of the three pineapple extracts may involve the contribution of ferulic acid. It also suggests that the three pineapple varieties may contain either no or very low amounts of tannic acid, catechin and also caffeic acid. 


\section{Macrothink}

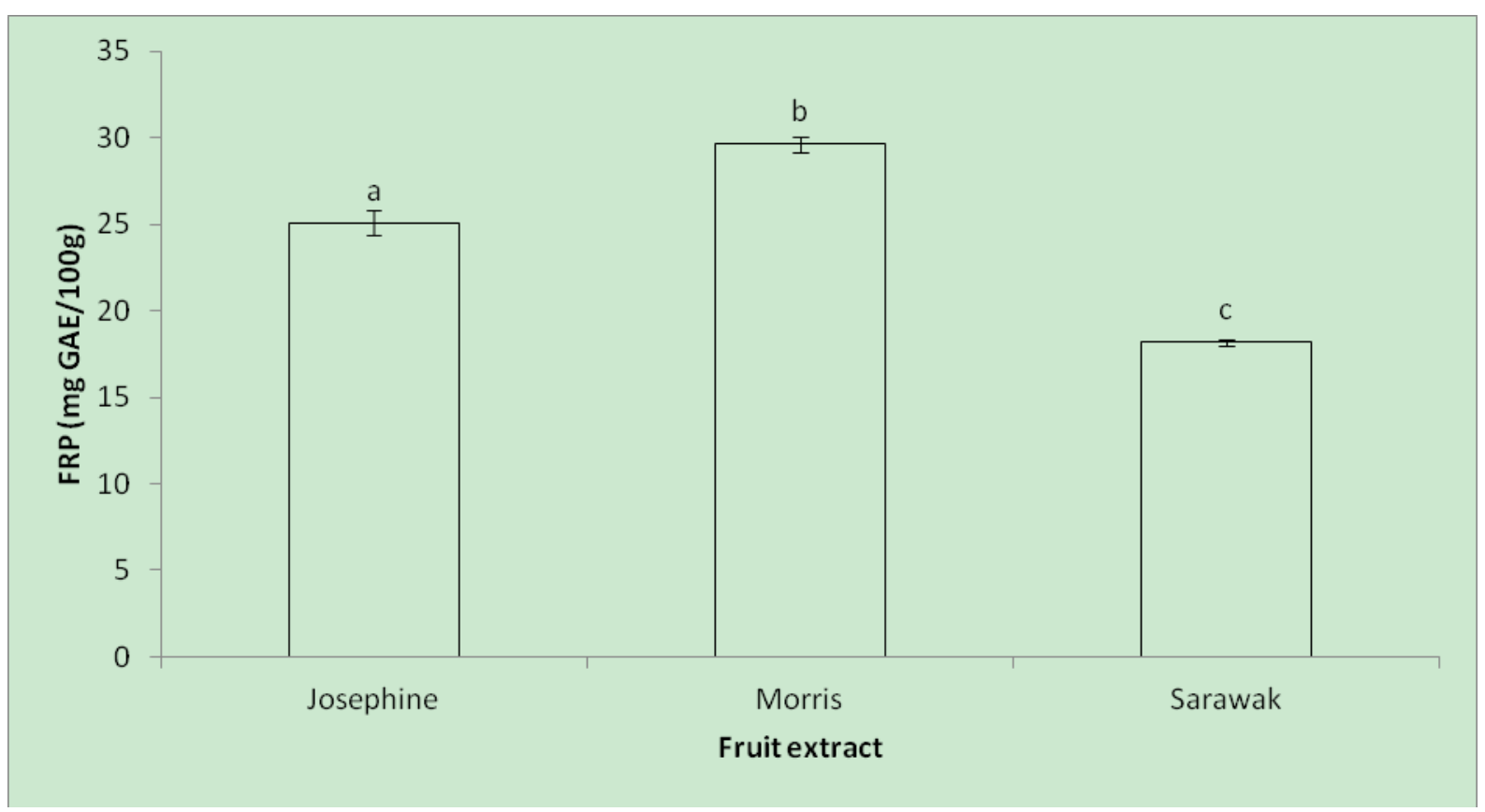

Figure 3. Ferric reducing power for the extracts of Josephine, Morris and Sarawak pineapple varieties

Values are the mean \pm SD of $\mathrm{n}=3$

Different lower case letters show significant differences $(\mathrm{P} \leq 0.05)$ between different pineapples

The corrected TPC (Figure 4) of the three pineapple extracts were plotted against their respected FRP value. A strong correlation $\left(\mathrm{R}^{2}=0.9475\right)$ was observed for the plot of TPC against FRP. This correlation may be due to a similar mechanism by which the Folin's reagent and FRP assay operates; both of which involve electron transfer (Contreras-Calderon et al., 2010). A high TPC value indicates the presence of more electron donors, which reduces ferric ion to ferrous ion. A weak correlation was observed when corrected TPC was plotted against FRP $\left(\mathrm{R}^{2}=0.158\right)$. This suggests that the phenolic compounds present in the extract did not solely contribute to the reducing ability of the extracts. Ascorbic acid also plays a role in contributing to the FRP of the pineapple extracts. 


\section{Mll Macrothink}

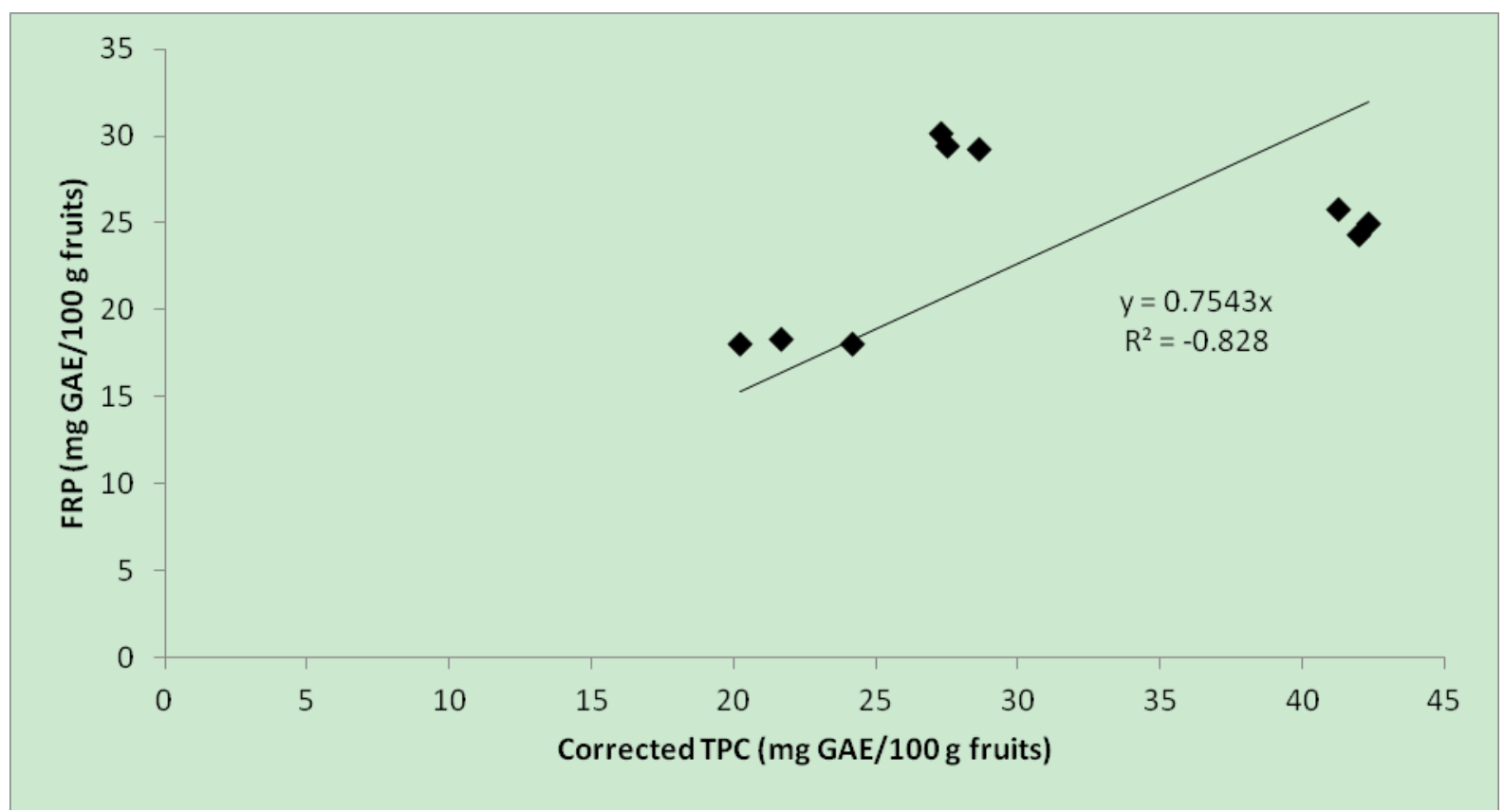

Figure 4. Correlation between the corrected TPC and FRP for the extracts of Josephine, Morris and Sarawak pineapple varieties

\subsubsection{Chelating power}

The chelating ability of an extract defines its ability to inhibit the formation of ferrous-ferrozine complex by chelating iron, competing with ferrozine (Lim et al., 2007). No previous studies have shown the chelating ability of pineapple extracts. It was observed that there was an increase in the iron chelating ability of the extracts with increasing concentration (Figure 5). The extract with the highest chelating ability was found to be Morris, which had an approximately $8 \%$ chelating ability compared to Josephine and Sarawak, which had an approximately $4 \%$ chelating ability. The chelating abilities of Josephine, Morris and Sarawak pineapples were low compared to other fruits such as banana $(55 \%)$ and star fruit $(30 \%)$, which have been reported by Lim et al. (2007). This result is important in determining if the three pineapple extracts were good or weak secondary antioxidants. As described earlier, secondary antioxidants are those antioxidants, which have the ability to chelate metal, thus preventing the initiation of radical chain reactions (Moure et al., 2001). Metal ions present in the biological system catalyse the Haber-Weiss and Fenton type reactions, generating hydroxyl radicals which results in the peroxidation of biological molecules (Chew et al., 2009). High chelating power of antioxidants will reduce free iron concentration, thus, reducing the extent of the Fenton reaction (Lim et al., 2007). The result of this study, therefore, shows that the three pineapple extracts behave as weak secondary antioxidants. 


\section{Macrothink}

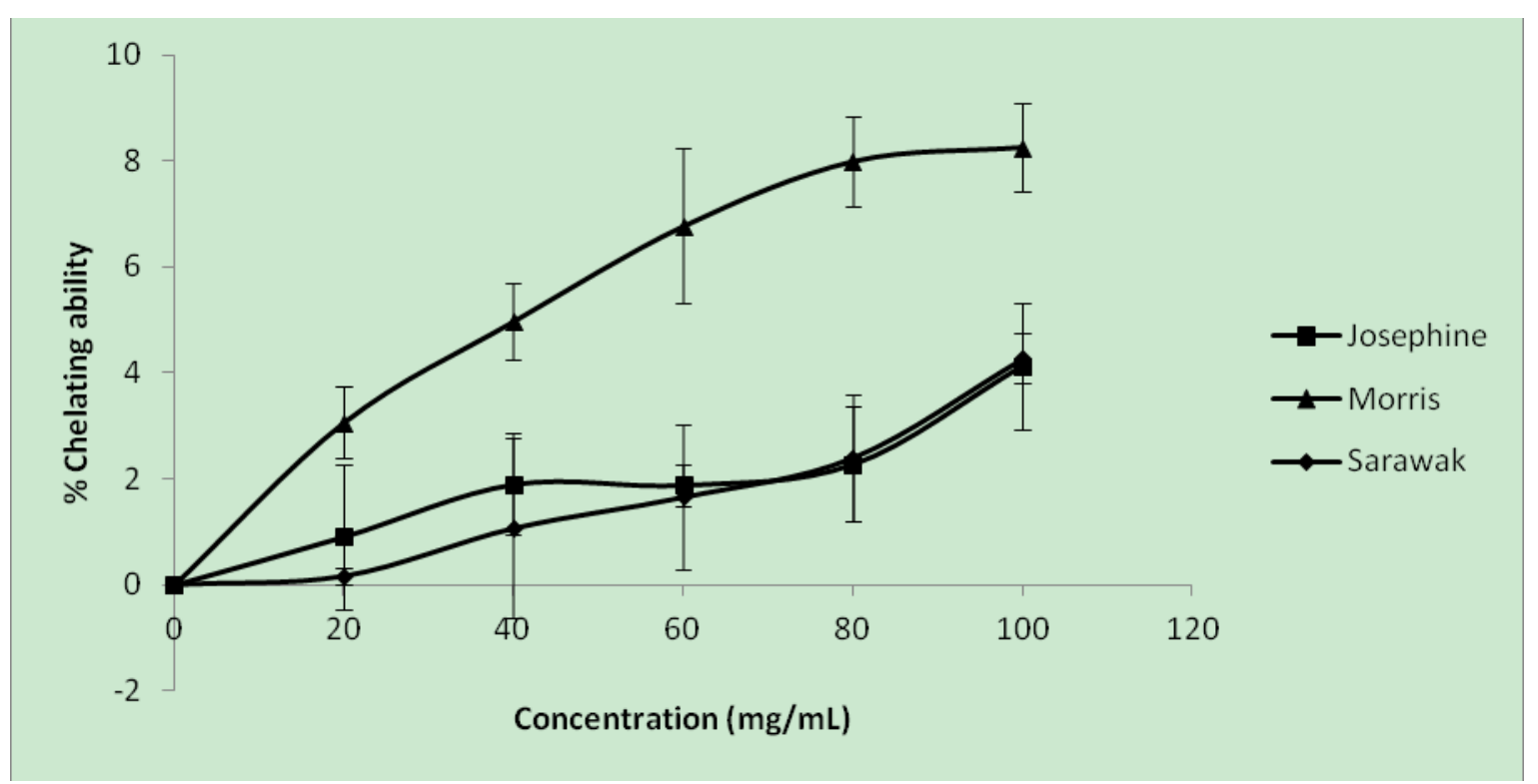

Figure 5. The iron chelating ability of the extract of Josephine, Morris and Sarawak

\section{Conclusion and future studies}

\subsection{Conclusion}

The antioxidant activity of the methanolic extracts of the Josephine, Morris, and Sarawak pineapple varieties were determined using the DPPH, FRP, and FIC assays. The best solvent system to extract the phenolic compounds of the three pineapples was found to be $50 \%$ methanol. Using 50\% methanol to extract their phenolic compounds, it was suggested that the phenolic compounds present in the three fruits were mostly polar. The different varieties of pineapples were found to contain different amount of phenolic compounds.

The results show that the extract of the Morris pineapple had the highest antioxidant activity among the three pineapple varieties that were studied as it had the highest scavenging activity $(25.2 \pm 0.5 \mathrm{mg} \mathrm{AA} / 100 \mathrm{~g}$ fruits), ferric reducing power (29.6 mg GAE/100 g fruits), and ferrous ion chelating ability ( $8 \% / 100 \mathrm{~g}$ fruits) compared to the extracts of the Josephine and Sarawak pineapple varieties. The ascorbic acid present in the three pineapples was suggested to be the main contributor towards the scavenging activity of the fruit. Study on the correlation between corrected TPC and FRP shows that the phenolic compounds are not the sole compounds which contribute toward the antioxidant activity of the fruit, rather a synergy of compounds are responsible. The different varieties of pineapples were found to possess different radical scavenging activities, ferric reducing powers, and iron chelating abilities. All of the extracts of the three pineapple varieties could act as primary antioxidants, but were weak secondary antioxidants.

\subsection{Future studies}

Because the antioxidant activity of the flesh and leaves of the pineapple have been studied, study could be designed to determine the antioxidant activity of the pineapple skin. Phenolic 
compounds present in different pineapples will allow better understanding of the antioxidant activity of the fruits. In order to further understand the antioxidant activity of the pineapple extracts, further study can be done using different antioxidant assays such as the oxygen absorbance capacity (ORAC) assay and the ABTS radical cation scavenging assay.

\section{Acknowledgement}

The authors would like to thank the School of Science, Monash University Malaysia, for providing funding for this study.

\section{References}

Alothman, M., Bhat, R., \& Karim, A.A. (2009). Antioxidant capacity and phenolic content of selected tropical fruits from Malaysia, extracted with different solvents. Food Chemistry, 115, 785 -788. http://dx.doi.org/10.1016/j.foodchem.2008.12.005

Bartolome, A.P., Ruperez, P., \& Fuster, C. (1994). Pineapple fruit: morphologicacl characteristics, chemical composition and sensory analysis of Red Spanish and Smooth $\begin{array}{lllll}\text { Cayenne } \quad \text { cultivars. } & \text { Food } & \text { 75-79. }\end{array}$ http://dx.doi.org/10.1016/0308-8146(95)95790-D

Carlier, J.D., Sousa, N.H., Santo, T.E., d'Eeckenbrugge, G.C., \& Leitao, J.M. (2010). A genetic map of pineapple (Ananas comosus (L.) Merr.) including SCAR, CAPS, SSR and EST-SSR markers. Molecular Breeding. http://dx.doi.org/10.1007/s11032-010-9543-9

Carter, P. (1971). Spectrophotometric determination of serum iron at the submicrogram level with a new reagent-ferrozine. Analytical Biochemistry, 40, 450-458. http://dx.doi.org/10.1016/0003-2697(71)90405-2

Chan, E.W.C., Lim, Y.Y., \& Chew, Y.L. (2007). Antioxidant activity of Camellia sinensis leaves and tea from a lowland plantation in Malaysia. Food Chemistry, 102, 1214-1222. http://dx.doi.org/10.1016/j.foodchem.2006.07.009

Contreras-Calderon, J., Calderon-James, L., Guerra-Hernandez, E., \& Garcia-Villanova, B. (2010). Antioxidant capacity, phenolic content and vitamin C in pulp, peel and seed from 24 exotic fruits from Colombia. Food Research International, 1-5. http://dx.doi.org/10.1016/j.foodres.2010.11.003

Damodaran, S., Parkin, K.L., \& Fennema, O.R. (2008). Fennema's food Chemistry. (4 ${ }^{\text {th }}$ ed.). USA: Taylor \& Francis Group.

de Mejia, E.G., Ramirez-Mares, M.V., \& Puangpraphant, S. (2009). Bioactive components of tea: Caner, inflammation and behavior. Brain, behavior, and immunity, 23, 721-731. http://dx.doi.org/10.1016/j.bbi.2009.02.013

De Silva, A.E., Kadir, M.A., Aziz, M.A., \& Kadzimin, S. (2008). Callus induction in pineapples (Ananas comosus L.) cv. moris and josapine. International Journal of Agricultural Research, 3, 261-267. http://dx.doi.org/10.3923/ijar.2008.261.267

Frankel, E.N. (2007). Antioxidants in food and biology: Facts and Fiction. USA: The oily 
press. http://dx.doi.org/10.1533/9780857097903

Guo, C., Yang, J., Wei, J., Li, Y., Xu, J., \& Jiang, Y. (2003). Antioxidant activities of peel, pulp and seed fractions of common fruits as determined by FRP assay. Nutrition Research, 23, 1719-1726. http://dx.doi.org/10.1016/j.nutres.2003.08.005

Haripyaree, A., Guneshwor, K., \& Damayanti, M. (2010). Evaluation of antioxidant properties of phenolics extracted from Ananas comosus L. Notulae Scientia Biologicae, 2(2), $68-71$.

Hossain, A., \& Rahman, S.M. (2010). Total phenolics, flavonoids and antioxidant activity of tropical fruit pineapple. Food Research International, 1-7. http://dx.doi.org/10.1016/j.foodres.2010.11.036

Hui, Y.H. (2007). Handbook of Food Products Manufacturing. USA: John Wiley \& Sons. http://dx.doi.org/10.1002/0470113553

Isabelle, M., Lee, B.L., Lim, M.T., Koh, W.P., Huang, D., \& Ong, C.N. (2010). Antioxidant activity and profiles of common fruits in Singapore. Food Chemistry, 123, 77-84 http://dx.doi.org/10.1016/j.foodchem.2010.04.002

Kongsuwan, A., Suthiluk, P., Theppakorn, T., Srilaong, V., \& Setha, S. (2009). Bioactive compounds and antioxidant capacity of phulae and nanglae pineapple. Asian Journal of Food and Agro-Industry, Special Issue, S44-S50.

Kou, M.C., Yen, J.H., Hong, J.T., Wang, C.L., Lin, C.W., \& Wu, M.J. (2009). Cyphomandra betacea Sendt. Phenolics protect LDL from oxidation and PC12 cells from oxidative stress. DWT-Food Science and Technology, 42, 458-463. http://dx.doi.org/10.1016/j.lwt.2008.09.010

Krings, U., \& Berger, R.G. (2001). Antioxidant activity of some roasted fiber. Journal of Agricultural Sciences, 2, 73-92.

Kudom, A.A., \& Kwapong, P.K. (2010). Floral visitors of Ananas comosus in Ghana: A preliminary assessment. Journal of Pollination Ecology, 2(5), 27-32.

Lima, L.A.R.S., Pimenta, L.P.S., \& Boaventura, M.A.D. (2010). Acetogenins from Annona cornifolia and their antioxidant capacity. Food Chemistry, 122, 1129-1138. http://dx.doi.org/10.1016/j.foodchem.2010.03.100

Makkar, H.P.S. (2003). Quantifications of tannins in tree and shrub foliage: A laboratory manual. Netherlands: Kluwer Academic Publishers. http://dx.doi.org/10.1007/978-94-017-0273-7

Maqsood, S., \& Benjakul, S. (2010). Comparative studies of four different phenolic compounds on in vitro antioxidative activity and the preventive effect on lipid oxidation of fish oil emulsion and fish mince. Food Chemistry, 119, 123-132. http://dx.doi.org/10.1016/j.foodchem.2009.06.004

Mhatre, M., Tilak-Jain, J., De, S., \& Devasagayam, T.P.A. (2009). Evaluation of the 
antioxidant activity of non-transformed and transformed pineapple: A comparative study. Food and Chemical Toxicology, 47, 2696-2702. http://dx.doi.org/10.1016/j.fct.2009.06.031

Moure, A., Cruz, J.M., France, D., Dominguez, J.M., Sineiro, J., Dominguez, H. et al. (2001). Natural Antioxidants from residual sources. Food Chemistry, 72, 145-171. http://dx.doi.org/10.1016/S0308-8146(00)00223-5

Oyaizu, M. (1986). Studies on products of browning reaction: antioxidative activity of products of browning reaction prepared from glucosamine. Japanese Journal of Nutrition, 44, 307-315. http://dx.doi.org/10.5264/eiyogakuzashi.44.307

Reddy, C.V.K., Sreermulu, D., \& Raghunath, M. (2010). Antioxidant activity of fresh and dry fruits commonly consumed in India. Food Research International, 43, 285-288. http://dx.doi.org/10.1016/j.foodres.2009.10.006

Robards, K. (2003). Strategies for the determination of bioactive phenols in plants, fruits and vegetables. Journal of Chromatography A, 1000, 657-691. http://dx.doi.org/10.1016/S0021-9673(03)00058-X

Scalzo, R.L. (2008). Organic acids influence on DPPH scavenging by ascorbic acid. Food Chemistry, 107, 40-43. http://dx.doi.org/10.1016/j.foodchem.2007.07.070

Singleton, V.L., \& Rossi, J.A. (1965). Colorimetry of total phenolics with phosphomolybdic-phosphotungstic acid reagents. Americal Journal of Enology and Viticulture, 16, 144-158.

Suntornsuk, L., Kritsanapun, W., Nilkamhank, S., \& Paochom, A. (2002). Quantitation of vitamin $\mathrm{C}$ content in herbal juice using direct titration. Journal of Pharmacceutical and Biochemical Analysis, 28, 849-855. http://dx.doi.org/10.1016/S0731-7085(01)00661-6

Valente, A., Albuquerque, T.G., Sanches-Silva, A., \& Costa, H.S. (2011). Ascorbic acid content in exotic fruits: A contribution to produce quality data for food composition databases. Food Research International, http://dx.doi.org/10.1016/j.foodres.2011.02.012

Vermerris, W., \& Nicholson, R. (2008). Phenolic compound biochemistry. USA: Springer Science.

\section{Copyright Disclaimer}

Copyright reserved by the author(s).

This article is an open-access article distributed under the terms and conditions of the Creative Commons Attribution license (http://creativecommons.org/licenses/by/3.0/). 